\title{
On the possible connection of the Comet Pons-Brooks with a Meteor Stream.
}

I desire to call attention to some slight evidence of the existence of a meteor stream which may possibly stand in some sort of connection with the comet Pons-Brooks. From an examination of all the available material of published meteor tracks in the interval Dec. 5 to Dec. 8 , I find that, after excluding those manifestly emanating from the well known and active radiants in Andromeda, Gemini, and Taurus, there remain 23 meteors observed by Heis on Dec. 8, about two thirds of them in 1847 and the rest in 1855,1857 and 1867 , and 10 meteors observed at
Vienna Dec. 7,1868 ; - all of which indicate a strongly marked radiant in Draco.

To determine the position of this radiant I employed the very convenient gnomonic chart of Sign. Lorenzoni (Mem. d. Soc. d. Spettrosc. Ital. V, I876) and calculated, according to the suggestion of Herr Ceraski, that point which gives the minimum sum of squares of perpendiculars to the various meteor paths.

I thus found the following radiants:

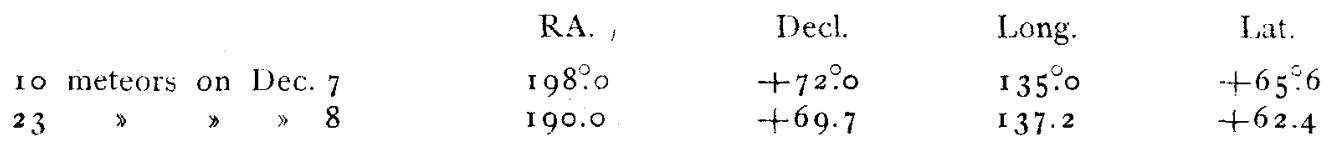

From these I derived the following orbits, to which I add for Comparison that of the Comet Pons-Brooks.

\begin{tabular}{c|c|c|c}
\hline & \multicolumn{2}{|c|}{ Meteors of } & Comet \\
& Dec. 7 & Dec. 8 & Pons-Brooks \\
\hline & I 883 & 1883 & 1 884 \\
$T$ & Dec. 28 & Dec. 23 & Jan. 25.82 \\
$\pi$ & 44.5 & $55^{\circ} .1$ & 93.21 \\
$\delta$ & 256.1 & 256.3 & $254 \quad 6$ \\
$i$ & 68.5 & 72.7 & 743 \\
$\log q$ & 9.9600 & 9.9784 & 9.8894 \\
$e$ & - & - & 0.9550
\end{tabular}

The resemblance is, therefore, not sufficient to give any considerable probability to the hypothesis of an intimate relation. On the other hand the position of the radiant from present data is too uncertain to enable us to pronounce against that hypothesis.

The difference in inclination and longitude of perihelion are not greater than are due to uncertainty in the observed radiant points; the $T$ and the node are of course of no significance in the comparison. The descending node of the comet's orbit lies at the distance 0.200 inside the earth's path, and the difference of perihelion

Harvard College Observatory 1883 Nov. I I. distance of the comet and the meteors is about o.I 5 . There is nothing in our present knowledge of the dimensions of meteor streams, or of the nature of their relations to comets, definite enough to render such a breadth as is here implied evidence against a possible connection. On the whole, therefore, it appears desirable that meteor observers should give close attention to the radiant in question, about the date of the earth's passage through the plane of the comet's orbit, Dec. 5 to Dec. $7 .^{\text {* }}$ ) Observations this year are likely to prove especially instructive on account of the proximity of the comet to this node.

\section{S. C. Chandler jr.}

*) Obige tufforderung wird leider den meisten Lesern zu spät zu Händen kommen; sie traf nicht so zeitig hier ein, als der Verfasser vorausgesetzt hat.

\section{In halt:}

Zu Nr.2561. Edivard S. Holden. Preliminary List of Errata in Yarnall's Catalogue. 261, - E.Schonfeld. Bemerkungen zu Herrn IIolden's . List of Frrata in Varnall's Catalogue". 267. - Simon Newcomb. Remarks on published corrections to Hausen's Lunar Tables. 269. - E. Schönfeld, Ein neuer Veränderlicher im Bilde Monoceros, 269. - W. Ceraski. Ueber Helligkeitsbestimmung sehr heller Sterne mit dem Zöllner'schen Photometer. 271. - W. Ceraski. Notiz in Bezug auf die Dırchsichtigkeit der Cometen. 27r. - Eaward S. Hoiden. Proper Motion of Lacaille 8262. 273. - L. Swift. Schreiben an den Herausgeber, 273. - S. C. Chandler. On the possible connection of the Comet Pons-Brooks with a Meteor Stream. 275. 